\title{
Development and First Year Results of a Psychosocial Surveillance System for Chronic Disease Related Health Behaviors
}

\author{
Jay E. Maddock, Carrie S. Marshall, Claudio R. Nigg, Jodi D. Barnett \\ University of Hawaii at Manoa
}

\begin{abstract}
Chronic diseases account for 7 out of 10 deaths in the United States and $60 \%$ of the Nation's health care expenses. Tobacco use, lack of physical activity and poor nutrition account for one third of US mortality. Behavioral surveillance systems such as the Behavioral Risk Factor Surveillance System (BRFSS) provide information on rates of behavior in the population and among different demographic categories. While these systems are essential for health promotion they do not assist the health educator in understanding psychosocial factors which may be related to the rates. A psychosocial surveillance system can aid in understanding the behavior change process and in the readiness of the population for behavior change. Results can assist states and localities in targeting health promotion messages and programs and can help in the allocation of often scarce health promotion funds. In 2000, the Hawaii Department of Health launched the Healthy Hawaii Initiative, a statewide program to reduce tobacco use, increase physical activity, and improve nutrition. As part of the evaluation, researchers at the University of Hawaii implemented a psychosocial surveillance system for the three target behaviors to assess changes in hypothesized mediators including stage of change, self efficacy, attitude and social norms. A random digit dial survey was conducted in the Spring and Fall of 2002 with 4,706 and 4,555 participants, respectively. Results show stability in the demographic characteristics and health behaviors of the sample but changes in the psychosocial variables. Several possible areas for interventions and messaging are demonstrated. A psychosocial surveillance system can be an important tool for health promotion and can lead to better understanding of health behaviors and attitudes.
\end{abstract}

(C) 2003 Californian Journal of Health Promotion. All rights reserved. Keywords: Surveillance, Chronic Disease, Health Behavior, Tobacco

Chronic diseases such as heart disease, cancer, and diabetes are now the leading causes of death and disability in industrialized countries and by 2015 the World Health Organization (WHO) estimates that they will surpass infectious diseases as the world's greatest killers (WHO, 1994). In the United States, these diseases account for seven of every ten deaths, affect the quality of life for 90 million Americans, and account for $60 \%$ of the Nation's one trillion dollar costs for medical care (WHO, 2002; Centers for Disease Control and Prevention (CDC), 2003a).

Three health behaviors - tobacco use, lack of physical activity, and poor nutrition - have been established as the "major causal risk factors" and account for 33\% of deaths in the United States (McGinnis \& Foege, 1993). Together, the burden of chronic disease caused by tobacco use, lack of physical activity, and poor nutrition cost the country $\$ 255$ billion dollars in medical expenditures in 2000 alone (CDC, 2003a).

Chronic diseases are the country's largest health burden; however they are also the most preventable. Through modifying risk behavior by eating healthy and exercising through the life span, studies estimate that up to $80 \%$ of cases of coronary heart disease, $90 \%$ of type 2 diabetes, and one-third of cancers could be prevented; furthermore, cessation in tobacco use could save 440, 000 lives per year (CDC, 2003a). The "critical link" (WHO, 2001) established between 
health risk behaviors and chronic disease provides the rationale for establishing public health programs and policies directed at changing the prevalence of these risk behaviors in populations.

Because these chronic conditions share an etiology based in behavioral risk factors, behavior surveillance is necessary to monitor trends and distribution of risk factors, monitor impact of policies and programs, and disseminate appropriate information (Pan American Health Organization, 1999). Behavioral risk factor surveillance involves "systematically collecting, analyzing, and interpreting data on behaviors people engage in to put their health at risk" (WHO, 2003). The US Centers for Disease Control and Prevention, for example, initiated the Behavioral Risk Factor Surveillance System (BRFSS) in 1984, and is now the world's largest telephone tracking system, with participation from all 50 states. The BRFSS systematically uses questionnaires to gather information on individual behaviors linked with chronic disease on a state-by-state basis. This information "is essential for planning and conducting public health programs at national, state, and local levels and evaluating these programs to ensure they are effective" (CDC, 2003b).

Behavioral surveillance to date has involved the collection of data regarding known behavioral risk factors to set prevention program priorities and develop targeted interventions. If the ultimate goal of a behavioral surveillance system is to "provide researchers with data so that they can design programs that will encourage adults to stop these behaviors" (CDC, 2003b), then data should extend beyond merely health behaviors, to an investigation into theoretical constructs including knowledge, attitudes and beliefs that predispose, enable, or reinforce these behaviors. Understanding not only the prevalence of these behaviors, but also the psychosocial context in which they take place is important in developing public health interventions.

Several models and theories of behavior change have been formulated to attempt to explain and predict outcomes by capturing the psychosocial factors that influence behavior. One widely used and tested theory is the Theory of Planned Behavior, an expectancy-value model used as a framework for deciphering individual actions by identifying, measuring, and combining beliefs that are relevant to individuals or groups (Ajzen, 1991). It assumes that behaviors are determined by behavioral intention, which is a function of attitudes towards the behavior, subjective norms (the individual's perception of whether referent others support their engagement in the behaviors) and perceived behavioral control (the individual's perception of control over performing the behavior). The antecedents to these predictor variables are behavioral, normative, and control beliefs weighted by the personal values of these beliefs. Construct measurement and analysis can then provide a basis for predicting and understanding healthy and unhealthy behaviors and outcomes of behaviors, and provides empirically identified targets for intervention (vonHaeften, Fishbein, Kasprzyk, \& Montaño, 2001).

The Theory's purpose is three-fold: to predict and understand motivational influences on behaviors that is not (partially or fully) under the individual's volitional control; to explain virtually any human behavior; and to identify how and where to target intervention strategies for changing behavior. It has been used to successfully predict and explain a wide range of health behaviors and intentions. A review of 56 studies found that all of these studies provided information to verify the efficacy of the Theory to explain intention to predict behavior for tobacco use, physical activity and nutrition among others (Godin \& Kok, 1996).

The Stage of Change construct of the Transtheoretical Model has gained widespread use over the past two decades and reflects behavior change as a "process-involving progress" through a series of stages (Prochaska, Redding, \& Evers, 2002, p.100). The model postulates that people move through a series of five stages of change in their attempts to modify their problem behaviors (Prochaska, DiClemente, \& Norcross, 1992). The five stages of change are precontemplation (not planning on 
changing), contemplation (considering change in the next six months), preparation (getting ready to change in the next month), action (currently changing), and maintenance (maintaining change for at least six months). This model has been explored in some naturalistic populations and found a stage distribution among smokers of $20 \%$ of smokers in the preparation stage, while approximately $40 \%$ are in the contemplation stage and $40 \%$ are in precontemplation (Velicer et al., 1995). Use of the stage of change measure on a population basis can assist a health educator in targeting messages to the appropriate level of readiness. In the example above, action-oriented cessation programs will be inappropriate for the large majority of smokers who are not ready to change (Velicer et al., 1995). The stage of change construct has been well validated across many areas of behavior change including tobacco use, nutrition and physical activity (Prochaska et al., 1994).

Currently, little work has been done in creating a psychosocial surveillance system for noncommunicable disease (NCD). According to the Pan American Health Organization (1999, p.16), "this is an area definitely in need of further development”. To begin closing this gap and to develop data-based recommendations for a statewide public health program, the Healthy Hawaii Initiative, we conducted two statewide, random, psychosocial surveillance surveys in the Spring of 2002 and Fall of 2002 on possible psychosocial correlates of three NCD risk behaviors - physical activity, nutrition, and tobacco use.

\section{Methods}

\section{Data Collection}

Two cross-sectional surveys using random digit dialing procedures of Hawaii's noninstitutionalized adult population were conducted February through April of 2002 and September through November of 2002 (Waksberg, 1978). The person over 18 who had the last birthday was asked to complete the interview to provide randomization within household. Informed consent was obtained over the phone. The survey took approximately 10 minutes to complete. All procedures were approved by the University of Hawaii
Committee on Human Subjects. Experienced interviewers were trained on the survey in both classroom and on live phone settings. Interviewers were guided by a computer aided telephone interview (CATI) system designed specifically for the survey. Skip patterns and out of range responses were automatically controlled by the system. To ensure that a representative sample was collected from all four of Hawaii's counties, a roughly equivalent number of respondents were sampled from each county. Cooperation rate was calculated by dividing the number of completed interviews by the number of completed interviews, refusals, terminations and language barriers.

\section{Measures}

Participants were asked a series of demographic questions, including age, sex, height, weight, education attained, income level, marital status, ethnic identification, home language, and perceived health. Standard demographic questions were obtained from the Behavior Change Consortium, a group of funded grantees sponsored by the National Institutes of Health (Ory, Jordan \& Bazzarre, 2002). Participants were then asked about their participation in three health behaviors:

1. Physical activity was assessed by the short form of the International Physical Activity Questionnaire (IPAQ). This instrument assesses time spent walking, sitting, and engaging in moderate and vigorous activity per week. High reliability and good validity with CSA accelerometers have been demonstrated in 12 countries (Craig et al., 2003). Respondents were categorized atrisk if they reported less than 150 minutes a week of walking or moderate physical activity or 60 minutes a week of vigorous activity (Pate et al., 1995).

2. Nutrition - Fruit and Vegetable intake was assessed using a short "all day" assessment developed by the National Cancer Institute (Thompson et al., 2002). This instrument has been shown to have good reliability compared to actual intake and is recommended for population based research (Thompson et al., 2002). Individuals were 
considered at-risk if they consumed less than 5 servings of fruits and vegetables per day.

3. Tobacco use - Tobacco use was assessed using standard measures recommended by the Society for Research on Nicotine and Tobacco (Hughes et al., 2003). Current smokers were identified as having smoked at least 100 cigarettes in their lifetime and currently (last month) smoking cigarettes. All current smokers were considered at-risk.

For each behavior, a series of psychosocial measures were also assessed. These included stage of change, attitude, subjective norm and self efficacy. Because of the limitations of the surveillance survey, one item indicators were used to assess each construct. An algorithm approach was used for stage of change, where respondents classified themselves into one of the five stage of change. For the constructs, responses were given on a ten point scale. The baseline attitudinal question asked if engaging in the target behavior was harmful to beneficial. Due to a ceiling effect, this was changed to unpleasant to pleasant at Wave II. For selfefficacy, respondents were asked how confident they were to perform (or not perform for smoking) the target behavior from not at all to extremely confident. For social norms, the respondents were asked if they thought people in general approved of the target behavior from strongly disagree to strongly agree.

\section{Analyses}

Data was analyzed using SPSS 11.5. Statewide data was weighted by gender and county to allow comparison with 2000 census estimates (US Census Bureau, 2001). Data are displayed descriptively using means, standard deviations and frequencies. For continuous variables, an independent sample t-test was used to assess differences. For categorical variables, chisquare tests were used. Analysis of variance was used with stage of change as the independent variable and other psychosocial indicators as the dependent variables.

\section{Results}

\section{Sample Characteristics}

The baseline sample was completed by 4,706 respondents. The follow-up was completed by 4,555 respondents. The cooperation rate was $34.5 \%$ for Wave I and 30.6\% for Wave II. Over 1,000 respondents completed the survey at each wave in all of Hawaii's four counties. The respondents were ethnically diverse with five ethnicities composing over $85 \%$ percent of the sample (Caucasian, Hawaiian, Japanese, Filipino and Chinese). The mean age was 46 and the mean education was 14 years. Both the baseline and follow-up sample were very similar. No significant differences were found for age, education, income, perceived health or body mass index. Small differences did exist for ethnicity and martial status. Demographic characteristics are presented in Table 1.

\section{Behavior}

At baseline, $82.7 \%$ of Hawaii residents were not eating five or more fruits and vegetables a day, with a non-significant increase to $84.0 \%$ at follow-up. No significant changes emerged across gender, ethnicity, and marital status. The youngest respondents and those having no college education had a significantly greater percent at risk while conversely, the oldest respondents had significantly fewer people at risk. Across both waves, males had a consistently higher percent at risk than females in each ethnicity group. At Wave II, 58.0\% of Hawaii residents were at risk for not getting enough physical activity, significantly higher than $50.1 \%$ seen in Wave I. It should be noted that the order of questions used to determine physical activity behavior were reversed during Wave II for a more accurate measurement: walking was asked first, followed by moderate activity, and vigorous. This is the likely contributor to the increase seen in percent at risk in Wave II. A greater percentage of females were at risk compared to males across all ethnic groups and at each wave. Tobacco use showed a non-significant increase from $16.5 \%$ to $18.0 \%$ from baseline to follow-up. No significant changes emerged across gender, ethnicity, or marital status. Those with less than a high school education had a higher percentage of smokers. The two youngest age groups were 
more at risk while the two oldest age groups were least at risk. Those who rated their health as poor had significantly more smokers. Across all ethnic groups, males had a higher percentage of smokers with the exception of Hawaiians in Wave I. No other significant changes were observed.

Table 1

Sample Characteristics of the Healthy Hawaii Surveillance Survey

\begin{tabular}{|c|c|c|c|}
\hline Demographic Variable & Total Wave I & Total Wave II & $\mathbf{p}$ \\
\hline \multicolumn{4}{|l|}{ Personal Characteristic } \\
\hline \% Male & 49.9 & 49.9 & \multirow[t]{2}{*}{ Weightec } \\
\hline \% Female & 50.1 & 50.1 & \\
\hline Mean age (SD) in years & $46.1(16.6)$ & $45.7(16.7)$ & NS \\
\hline \% Caucasian & 33.0 & 35.2 & \multirow[t]{6}{*}{$\mathrm{p}<.01$} \\
\hline \% Hawaiian/Part Hawaiian & 15.6 & 17.8 & \\
\hline \% Japanese & 21.3 & 20.8 & \\
\hline \%Filipino & 11.5 & 10.8 & \\
\hline \% Chinese & 4.6 & 4.5 & \\
\hline \% English spoken in home & 93.8 & 93.4 & \\
\hline Mean years education (SD) & $14.4(3.1)$ & $14.5(3.4)$ & NS \\
\hline Median Income & $\$ 40-49,000$ & $\$ 40-49,000$ & NS \\
\hline \multicolumn{4}{|l|}{ Household Characteristics } \\
\hline \% Married & 56.3 & 58.2 & \multirow[t]{2}{*}{$\mathrm{p}<.05$} \\
\hline \% Never married & 22.2 & 21.0 & \\
\hline \multicolumn{4}{|l|}{ Perceived Health Related Characteristics } \\
\hline Mean BMI (SD) & $25.6(5.0)$ & $25.7(5.1)$ & NS \\
\hline \% Perceived Very good/excellent health & 44.6 & 43.4 & NS \\
\hline
\end{tabular}

\section{Stage of Change}

For fruit and vegetable consumption, almost half of the population ( $46.5 \%$ both waves) reported being in the preparation stage of change. For physical activity, about a third (34.6\% both surveys) reported being in preparation while over half (53.0\% both survey) reported being in precontemplation. Among smokers, very few
(13.3\% both surveys) were planning on quitting in the next month, while the rest of smokers were fairly evenly distributed in the precontemplation and contemplation stages of change. For all behaviors, the percentage in precontemplation increased significantly from baseline to follow-up. Table 2 displays the stage distribution for each of the behaviors.

Table 2

Stage of Change for Baseline and Follow-Up for Individuals At-Risk

\begin{tabular}{|l|c|c|c|c|c|c|}
\hline & \multicolumn{2}{|c|}{ Physical Activity* } & \multicolumn{2}{c|}{ Nutrition* } & \multicolumn{2}{c|}{ Tobacco* } \\
\hline \multicolumn{1}{|c|}{ Stage of Change } & $\begin{array}{c}\text { Wave I } \\
\mathrm{n}=1,739\end{array}$ & $\begin{array}{c}\text { Wave II } \\
\mathrm{n}=1,876\end{array}$ & $\begin{array}{c}\text { Wave I } \\
\mathrm{n}=3,697\end{array}$ & $\begin{array}{c}\text { Wave II } \\
\mathrm{n}=3,667\end{array}$ & $\begin{array}{c}\text { Wave I } \\
\mathrm{n}=705\end{array}$ & $\begin{array}{c}\text { Wave II } \\
\mathrm{n}=758\end{array}$ \\
\hline & $\%$ & $\%$ & $\%$ & $\%$ & $\%$ & $\%$ \\
\hline Precontemplation & 50.2 & 55.6 & 44.5 & 48.8 & 42.4 & 47.2 \\
\hline Contemplation & 13.5 & 11.4 & 7.0 & 6.8 & 46.5 & 37.3 \\
\hline Preparation & 36.3 & 33.0 & 48.5 & 44.5 & 11.1 & 15.4 \\
\hline
\end{tabular}

$* \mathrm{p}<.05$, significant difference in stage distribution across waves 


\section{Theory of Planned Behavior} Constructs Significant decreases were seen in social norms for both tobacco use and physical activity. At baseline, the attitude questions assessed if the target behavior was harmful or beneficial. Responses were highly skewed (-2.2 to -3.5$)$, prompting replacement of the anchors with unpleasant to pleasant. This reduced skew from -0.85 to 0.05 . Attitude scores significantly decreased as a result of the changed anchors. The construct means by wave are displayed in Table 3. Bivariate correlations between the constructs and behavior were also examined using Wave II data for physical activity and nutrition. Both self efficacy $(\mathrm{r}=.46, \mathrm{p}<.001)$ and attitude $(\mathrm{r}=.32, \mathrm{p}<.001)$ had strong relationships with fruit and vegetable intake. A small negative relationship $(\mathrm{r}=-.07, \mathrm{p}<.001)$ was seen for social norms. For physical activity, self efficacy $(r=.24, p<.001)$ was strongly related to total physical activity. A small relationship was seen for attitude $(\mathrm{r}=.09$, $\mathrm{p}<$ .001) and no relationship was seen with social norms.

\section{Integrating Stage of Change With Other Behaviors}

As a heuristic for understanding the other constructs, we conducted ANOVAs with stage of change as the grouping variable and behavior, attitude, social norm and self efficacy as the dependent variables using Wave II data only. Results showed that self efficacy increased linearly across the stage. Behavior was also consistently related to stage. Attitude increased linearly across stages for fruit and vegetable intake, but only changed between precontemplation and maintenance for physical activity and between precontemplation and the other stages for tobacco use. Social norms showed a weak relationship across all of the behaviors. Wave I data is available from the first author and shows a similar pattern.

Table 3

Mean and Standard Deviation for Psychosocial Mediators Across Three Health Behaviors

\begin{tabular}{|l|c|c|c|c|c|c|}
\hline & \multicolumn{2}{|c|}{ Physical Activity } & \multicolumn{2}{c|}{ Nutrition } & \multicolumn{2}{c|}{ Tobacco $^{2}$} \\
\hline Mediator & $\begin{array}{c}\text { Wave I } \\
\mathrm{n}=4,172\end{array}$ & $\begin{array}{c}\text { Wave II } \\
\mathrm{n}=4,456\end{array}$ & $\begin{array}{c}\text { Wave I } \\
\mathrm{n}=4,648\end{array}$ & $\begin{array}{c}\text { Wave II } \\
\mathrm{n}=4,477\end{array}$ & $\begin{array}{c}\text { Wave I } \\
\mathrm{n}=694\end{array}$ & $\begin{array}{c}\text { Wave II } \\
\mathrm{n}=742\end{array}$ \\
\hline $\begin{array}{l}\text { Self- } \\
\text { Efficacy }\end{array}$ & $7.51(2.87)$ & $7.32(3.08)^{*}$ & $7.06(2.66)$ & $6.74(2.82)^{*}$ & $5.72(3.13)$ & $5.46(3.25)$ \\
\hline Attitude & $9.30(1.57)$ & $7.52(2.50)^{1}$ & $9.06(3.10)$ & $7.37(2.74)^{1}$ & $8.89(2.24)$ & $5.12(3.73)^{1}$ \\
\hline $\begin{array}{l}\text { Social } \\
\text { Norms }\end{array}$ & $8.00(2.29)$ & $7.68(2.50)^{*}$ & $5.60(3.10)$ & $4.86(3.10)$ & $8.56(2.24)$ & $7.80(2.85)^{*}$ \\
\hline
\end{tabular}

Attitude questions were changed between Wave I and Wave II

2 Data is reported on current smokers only

* $\mathrm{p}<.05$ 
Table 4

Behavior and Mediators by Stage of Change

\begin{tabular}{|c|c|c|c|c|}
\hline & \multicolumn{4}{|c|}{ Fruit and Vegetable Intake } \\
\hline \multirow[t]{2}{*}{ Stages } & Behavior $^{1}$ & Attitude & Social Norm & Self Efficacy \\
\hline & M (SD) & M (SD) & M (SD) & M (SD) \\
\hline Precontemplation & $2.00(1.05)$ & $6.39(2.81)$ & $4.96(2.94)$ & $5.17(2.77)$ \\
\hline Contemplation & $2.07(1.07)$ & $7.00(2.37)$ & $5.02(2.91)$ & $5.99(2.39)$ \\
\hline Preparation & $2.53(1.07)$ & $7.92(2.44)$ & $4.87(3.18)$ & $7.62(2.20)$ \\
\hline Action & $5.55(1.15)$ & $8.24(2.24)$ & $4.73(2.95)$ & $7.77(2.12)$ \\
\hline Maintenance & $5.79(1.25)$ & $8.99(2.12)$ & $4.46(3.39)$ & $9.28(1.54)$ \\
\hline $\mathrm{p}$ & $<.001$ & $<.001$ & $<.05$ & $<.001$ \\
\hline \multirow[t]{3}{*}{$\eta^{2}$} & .598 & .123 & .003 & .289 \\
\hline & \multicolumn{4}{|c|}{ Physical Activity } \\
\hline & Behavior $^{1}$ & Attitude & Social Norm & Self Efficacy \\
\hline Precontemplation & $\mathrm{M}(\mathrm{SD})$ & M (SD) & M (SD) & M (SD) \\
\hline Contemplation & $683.9(1107.7)$ & $6.54(2.91)$ & $7.53(2.67)$ & $4.63(3.29)$ \\
\hline Preparation & $691.9(907.5)$ & $7.19(2.08)$ & $7.79(2.32)$ & $6.46(2.96)$ \\
\hline Action & $928.7(1227.8)$ & $7.13(2.33)$ & $7.67(2.44)$ & $6.84(2.72)$ \\
\hline Maintenance & $1178.3(1218.3)$ & $7.19(2.35)$ & $7.28(2.71)$ & $7.26(2.71)$ \\
\hline $\mathrm{p}$ & $1328.8(1351.4)$ & $8.18(2.18)$ & $7.82(2.42)$ & $8.81(2.02)$ \\
\hline \multirow[t]{5}{*}{$\eta^{2}$} & $<.001$ & $<.001$ & $<.01$ & $<.001$ \\
\hline & .048 & .076 & .004 & .302 \\
\hline & \multicolumn{4}{|c|}{ Tobacco Use ${ }^{2}$} \\
\hline & Behavior $^{1}$ & Attitude & Social Norm & Self Efficacy \\
\hline & M (SD) & M (SD) & M (SD) & $\mathrm{M}(\mathrm{SD})$ \\
\hline Precontemplation & $15.6(10.1)$ & $4.70(3.66)$ & $7.22(3.14)$ & $4.90(3.50)$ \\
\hline Contemplation & $13.9(9.5)$ & 5.54 (3.69) & $8.43(2.34)$ & $5.79(2.96)$ \\
\hline Preparation & $12.3(11.1)$ & $5.30(3.95)$ & $7.93(2.76)$ & $6.34(2.91)$ \\
\hline Action & ---- & ----- & ----- & ----- \\
\hline Maintenance & ---- & ---- & ---- & ---- \\
\hline $\mathrm{p}$ & $<.01$ & $<.05$ & $<.001$ & $<.001$ \\
\hline$\eta^{2}$ & .014 & .011 & .037 & .029 \\
\hline
\end{tabular}

Behavior is defined as: A) average servings of fruits and vegetables per day; B) minutes of physical activity per week; and C) cigarettes per day.

2 Only current smokers are included.

\section{Discussion}

In the Spring and Fall of 2002, two crosssectional surveys were conducted to evaluate physical activity, fruit and vegetable consumption and tobacco use behaviors of Hawaii residents. The surveys marked the initiation of a population-based surveillance system to determine current participation in the three behaviors, readiness to change to meet professionally recommended guidelines, and the psychosocial indicators - confidence, attitude, perceived behavioral control, and social norms that mediate these behaviors.

Demographic variables were similar across the two waves of the study. No significant 
differences were observed for tobacco use and inadequate fruit and vegetable consumption across the 6 month waves. In contrast, participants not meeting recommended levels of physical activity showed a significant increase across waves. However, it should be noted that the order of questions used to determine physical activity behavior were reversed during Wave II for a more accurate measurement. This is the likely contributor to the increase seen at Wave II.

Stage of Change distributions for the three behaviors changed slightly with individuals more likely to be in the precontemplation stage of change. Although few individuals reported consuming 5 fruits and vegetables a day, almost half were planning to start eating 5 or more a day in the next month. Among physically inactive people, about a third was thinking about changing in the next month. For tobacco use, approximately equal numbers of smokers were in the precontemplation and contemplation stage for quitting, while significantly fewer (15\%) were in the preparation stage. These findings indicate different approaches for modifying behaviors. An "action-based" approach is probably the best method for increasing fruit and vegetable intake. High motivation exists among many of the respondents so cues to action like supermarket tags and indicators on restaurant menus might help. For tobacco, most people are not ready to change. "Action-based" interventions like quit lines are likely to be called by very few people. Interventions based on decreasing barriers and increasing benefits might be more applicable.

The development of a new surveillance system is an iterative process. Data from Wave 1 showed that almost all respondents thought that physical activity and eating fruits and vegetables was beneficial and that smoking was harmful. This was an important lesson for health educators not to dwell on this message. During the second wave we found people much more mixed on how pleasant physical activity and eating fruits and vegetables is and how unpleasant quitting smoking is. The ability to change questions for what is salient in the population is an important facet of a surveillance system. Although several studies have found social norms related to behavior, we found little evidence that social norms were related to behavior or stage of change. One reason may have been that we measured global social norms (ie. People in general) not ones related to specific peer and family groups. This question will be changed in the future. For now, our campaign will not try to promote a global social norm message. Self efficacy was a strong predictor across all behaviors. Approaches that are designed to increase efficacy are hypothesized to be successful in changing behavior.

Only small changes were seen in the psychosocial factors during the six month period. Some of these may have been due to seasonal effects. Data on population-based psychosocial surveillance collection are rare and information on implementation is not widely available in the literature. Thus, the content and conduction of these surveys was exploratory. Future attempts at surveys of this nature are important because data on psychosocial indicators provides an important picture of prevalent norms and attitudes influencing risk behaviors for chronic diseases. According to the WHO (Bonita, de Courten, Dwyer, Jamrozik, \& Winkelmann, 2001), the need for this type of surveillance systems to collect quality information regarding the determinants of health behavior related to chronic diseases has gone "unrecognized." With few exceptions, psychosocial surveillance systems have existed exclusively within the realm of HIV/AIDS surveillance. For example, a decade ago the National Commission on AIDS (1993, pgs. 4-9) called for "behavioral and social sciences to be properly integrated into the mainstream response in the US" with the data from psychosocial surveillance to be used "as a tool for developing effective means to reach people at risk, delineate the obstacles to behavior change, and to determine language and styles of communication among various population groups”. Many countries, for example Jamaica (Branson, 2001), have implemented population- based psychosocial surveillance systems to identify the behavioral determinants and develop effective approaches to achieving behavior change in 
those most at risk for HIV infection. A similar psychosocial surveillance system could help aid in the description of the chronic disease burden and provide novel opportunities for intervention. In Hawaii, we recently completed the third wave in Spring 2003. This will be our last 6 month wave with the next survey scheduled for Spring 2004. In other communities, this survey could be conducted biannually. Another possibility may be to add these indicators to existing noncommunicable disease surveillance methods. For example, the WHO's Stepwise surveillance system for tracking non-communicable diseases allows for an optional module to be added to the questionnaire for "items aimed at program development and evaluation such as attitudes, beliefs, and barriers related to the CORE items (tobacco use, alcohol consumption, physical activity, and fruit/vegetable consumption)" (Bonita et al., 2001). The CDC could also examine adding a set of questions to the optional modules of the BRFSS that would allow individual states to include similar psychosocial indicators.
A psychosocial surveillance system does have several limitations. First, reliance on telephone self report is necessary to reach the population. Second, even with only three behaviors it is necessary to restrict the numbers of questions in each area making single item indicators the norm. Third, with telemarketing becoming more and more common, people are less willing to answer their telephones introducing a response bias which is difficult to measure. The cooperation rate was somewhat low although not much different than many health surveys. Since we were using random digit dial procedures many of the refusals may have been nonresidential numbers. This is impossible to calculate. The increasing number of cellular only households is also diminishing the representativeness of these procedures. However, despite these limitations, a psychosocial surveillance system can be an important tool for health promotion.

\section{References}

Ajzen, I. (1991). The theory of planned behavior. Organizational Behavior and Human Decision Processes, 50, 179-211.

Bonita, R., de Courten, M., Dwyer, T., Jamrozik, K., \& Winkelmann, R. (2001). Surveillance of risk factors for noncommunicable diseases: Summary of the who stepwise approach. Retrieved July 10, 2003, from http://www.who.int/ncd/surveillance/surveillance_publications.htm

Branson, B. M. (2001). Assessment of Jamaica's HIV/AIDS surveillance system: A CDC report. Retrieved July 10, 2003, from http://www.hivlacepinet.org/media/files/Jamaica\%20Surveillance\%20final\%20.doc

Centers for Disease Control and Prevention. (2003a). Preventing chronic diseases: Investing wisely in health fact sheets. Retrieved July 10, 2003, from http://www.cdc.gov/nccdphp/pe factsheets

Centers for Disease Control and Prevention. (2003b). The behavioral risk factor surveillance system. Retrieved July 10, 2003, from http://www.cdc.gov/nccdphp/aag/aag brfss.htm and http://www.cdc.gov/nccdphp/bb brfss yrbss/index.htm

Craig, C. L., Marshall, A. L., Sjostrom, M., Bauman, A. E., Booth, M. L., Ainsworth, B. E., Pratt, M., Ekelund, U., Yngve, A., Sallis, J.F., \& Oja, P. (2003). International physical activity questionnaire: 12-country reliability and validity. Medicine and Science in Sports and Exercise, 35, 1381-1395

Godin, G., \& Kok, G. (1996). The theory of planned behavior: A review of its applications to healthrelated behaviors. American Journal of Health Promotion, 11, 87-98.

Hughes, J. R., Keely, J. P., Niaura, R. S., Ossip-Klein, D. J., Richmond, R. L., \& Swan, G. E. (2003). Measures of abstinence in clinical trials: Issues and recommendations. SRNT Subcommittee on Abstinence Measures. Unpublished Manuscript.

McGinnis, J. M., \& Foege, W. H. (1993). Actual death in the United States. Journal of the American Medical Association, 270, 2207-2212. 
National Commission on AIDS. (1993). Behavioral and social sciences and the HIV/AIDS epidemic. Washington, DC: National Commission on AIDS, July 1993.

Ory, M. G., Jordan, P. J., \& Bazzarre, T. (2002). The behavior change consortium: Setting the stage for a new century of health behavior change research. Health Education Research, 17, 500-511.

Pan American Health Organization. (1999). Networking for the surveillance of risk factors for noncommunicable diseases in Latin America and the Caribbean. PAHO Proposal, 99.08.

Pate, R. R., Pratt, M., Blair, S. N., Haskell, W. L., Macera, C. A., Bouchard, C., Buchner, D., Ettinger, W., Heath, G.W., \& King, A.C. (1995). Physical activity and public health. A recommendation from the Centers for Disease Control and Prevention and the American College of Sports Medicine. Journal of the American Medical Association, 273, 402-407.

Prochaska, J. O, Velicer, W. F., Rossi, J. S., Goldstein, M. G., Marcus, B. H., Rakowski, W., Fiore, C., Harlow, L.L., Redding, C.A., Rosenbloom, D., \& Rossi, S.R. (1994). Stages of change and decisional balance for 12 problem behaviors. Health Psychology, 131, 39-46.

Prochaska, J. O., DiClemente, C. C., \& Norcross, J. C. (1992). In search of how people change: Applications to addictive behaviors. American Psychologist, 47, 1102-1112.

Prochaska, J. O., Redding, C. A., \& Evers, K. E. (2002). The transtheoretical model and stages of change. In K. Glanz, B. K. Rimer, \& F. M. Lewis (Eds.), Health behavior and health education: Theory, research, and practice (3rd Ed.). San Francisco: Jossey-Bass, Inc.

Thompson, F. E., Subar, A. F., Smith, A. F., Midthune, D., Radimer, K. L., Kahle, L. L., \& Kipnis, V. (2002). Fruit and vegetable assessment: Performance of 2 new short instruments and a food frequency questionnaire. Journal of the American Dietetic Association, 102, 1764-72.

U. S. Census Bureau. (2001). US census data for the state of Hawaii. Retrieved July 20, 2003, from http://www.census.gov/census2000/states/hi.html

Velicer, W. F., Fava, J. L., Prochaska, J. O., Abrams, D. B., Emmons, K. M., \& Pierce, J. (1995). Distribution of smokers by stage in three representative samples. Preventive Medicine, 24, 401411.

von Haeften, I., Fishbein, M., Kasprzyk, D., \& Montaño, D. (2001). Analyzing data to obtain information to design targeted interventions. Psychology, Health \& Medicine, 6(2), 151-164.

Waksberg, J. (1978). Sampling methods for random digit dialing. Journal of the American Statistical Association, 73, 40-46.

World Health Organization. (1994). Cardiovascular disease risk factors: New areas for research: Report of a WHO study group. WHO Technical Report Series, No. 841. Geneva.

World Health Organization. (2001). WHO mega country health promotion network: Summary report from the 2nd population-based noncommunicable disease (NCD) behavioral risk factor surveillance meeting. Geneva, World Health Organization, December 3-5, 2001.

World Health Organization. (2002). Diet, physical activity, and health. Fifty-Fifth World Health Assembly: Provisional agenda item 13.11. March 27, 2002. Retrieved July 10, 2003, from http://www.who.int/gb/EB WHA/PDF/WHA55/ea5516.pdf

World Health Organization. (2003). What is behavioral risk factor surveillance? Retrieved July 10, 2003, from http://www.who.int/hpr/brfs/index.shtml

\section{Acknowledgements}

This project was made possible by funding from the Hawaii Tobacco Settlement Funds through a contract with the Hawaii Department of Health. 


\author{
Author Information \\ Jay Maddock, Ph.D.* \\ Assistant Professor \\ Department of Public Health Sciences and Epidemiology \\ University of Hawaii at Manoa \\ 1960 East-West Rd. \\ Honolulu, HI 96822 \\ Ph. 808-956-5779 \\ Fax. 808-956-6041 \\ E-Mail: jmaddock@hawaii.edu
}

Carrie S. Marshall

Claudio R. Nigg

Jodi D. Barnett

University of Hawaii at Manoa

* corresponding author 